\title{
BMJ Open Biomarkers of necrotising soft tissue infections: aspects of the innate immune response and effects of hyperbaric oxygenation - the protocol of the prospective cohort BIONEC study
}

\author{
Marco Bo Hansen, ${ }^{1}$ Ulf Simonsen, ${ }^{2}$ Peter Garred, ${ }^{3}$ Ole Hyldegaard ${ }^{1}$
}

To cite: Hansen MB, Simonsen U, Garred P, et al. Biomarkers of necrotising soft tissue infections: aspects of the innate immune response and effects of hyperbaric oxygenation-the protocol of the prospective cohort BIONEC study. BMJ Open 2015;5:e006995. doi:10.1136/bmjopen-2014006995

- Prepublication history for this paper is available online To view these files please visit the journal online (http://dx.doi.org/10.1136/ bmjopen-2014-006995).

Received 22 October 2014 Revised 21 April 2015 Accepted 23 April 2015 CrossMark

${ }^{1}$ Department of Anaesthesia, Centre of Head and Orthopaedics, Copenhagen University Hospital, Rigshospitalet, Denmark 2Department of Biomedicine, Pulmonary and Cardiovascular

Pharmacology, University of Aarhus, Aarhus, Denmark ${ }^{3}$ Laboratory of Molecular Medicine, Department of Clinical Immunology, Copenhagen University Hospital, Rigshospitalet, Denmark

Correspondence to Dr Marco Bo Hansen; marcobhansen@gmail.com

\section{ABSTRACT}

Introduction: The mortality and amputation rates are still high in patients with necrotising soft tissue infections (NSTIS). It would be ideal to have a set of biomarkers that enables the clinician to identify highrisk patients with NSTI on admission. The objectives of this study are to evaluate inflammatory and vasoactive biomarkers as prognostic markers of severity and mortality in patients with NSTI and to investigate whether hyperbaric oxygen treatment (HBOT) is able to modulate these biomarkers. The overall hypothesis is that plasma biomarkers can be used as prognostic markers of severity and mortality in patients with NSTI and that HBOT reduces the inflammatory response.

Methods and analysis: This is a prospective, observational study being conducted in a tertiary referral centre. Biomarkers will be measured in 114 patients who have been operatively diagnosed with NSTI. On admission, baseline blood values will be obtained. Following surgery and HBOT, daily blood samples for measuring regular inflammatory and vasoactive biomarkers (pentraxin-3, interleukin-6 and nitrite) will be acquired. Samples will be analysed using validated ELISA assays, chemiluminescence and Griess reaction. Clinical data will be obtained during admission in the intensive care unit for a maximum of 7 days. The primary analysis will focus on pentraxin-3, interleukin- 6 and nitrite as early markers of disease severity in patients with NSTI.

Ethics and dissemination: The study has been approved by the Regional Scientific Ethical Committee of Copenhagen (H-2-2014-071) and the Danish Data Protection Agency (J. no. 30-0900 and J. no. 30-1282). Results will be presented at national and international conferences and published in peerreviewed scientific journals.

Trial registration: NCT02180906.

\section{INTRODUCTION}

Necrotising soft tissue infection (NSTI) is a complex, multifactorial disease with a diverse microbiological aetiology. ${ }^{1}$ The rapid spread

\section{Strengths and limitations of this study}

- It will be the largest published single-centre study cohort of patients with necrotising soft tissue infections (NSTI) exploring biomarkers during admission.

- It is the first protocol planning to study biomarkers in patients receiving hyperbaric oxygen treatment (HBOT)

- Data collection will be prospectively performed.

- Its outcomes may provide decision makers with valuable clinical and biochemical evidence that can be used as a template for shared internal guidelines and future randomised clinical trials.

- The biomarkers are not specific for NSTI.

- This study may be subject to potential biases inherent to the non-randomised design and uneven HBOT allocation.

of infection may cause extensive soft tissue damage, limb loss and multiple organ failure. The incidence of NSTIs has increased over the past years and the mortality rates remain high $(20-30 \%)$ despite increased focus on these patients. ${ }^{1}{ }^{2}$ The extensive inflammatory response is thought to be the main cause of mortality. ${ }^{3}$

Biomarkers are used in clinical settings to manage care of patients, for example, predicting disease outcome. Therefore, it would be favourable to be able to identify patients with NSTI on admission who have a highfatality risk or risk of amputation, thereby directing aggressive treatment in these subgroups in order to cease disease progression, just as it would be favourable to identify the patients without the need for extensive and invalidating surgery. The triage of patients with NSTI according to disease severity based on an objective measure such as a blood test 
would be ideal. However, it is unknown which biomarkers are involved in the inflammatory response in patients with NSTI and how these molecular mediators are modulated during the infection and treatment regimes. Thus, there is a need for a novel insight into the disturbance of the immune system disturbances in order to improve the outcome of NSTIs. This study seeks to increase the insight of the innate immune response in patients with NSTI through the investigation of three major groups of biomarkers: acute-phase proteins, cytokines and vasoactive biomarkers.

\section{Study I: acute-phase proteins as biomarkers in NSTI}

Pentraxin-3 (PTX3) is induced at the onset of inflammation. It is an interesting biomarker since studies have demonstrated an association between high concentrations of PTX3 and mortality and disease severity in patients with infections. ${ }^{4-10}$ Like PTX3, C reactive protein (CRP) is a member of the pentraxin superfamily of proteins and a widely used biomarker for bacterial infections. ${ }^{11}$ However, procalcitonin (PCT) has proven to be a better indicator for sepsis than CRP and shown itself to be closely related to severity of sepsis and organ dysfunction. ${ }^{12-14}$ These acute-phase proteins, among others, will be investigated in the first study.

\section{Study II: cytokines as biomarkers in NSTI}

Proinflammatory cytokines are released in great amounts during septic shock. Currently, it is unknown whether the same response takes place in patients with NSTI. Interleukin (IL)-1 $\beta$ is increased in septic patients compared to non-septic patients, ${ }^{15}$ while IL-6, IL-10 and tumour necrosis factor $\alpha(\mathrm{TNF}-\alpha)$ can be used to differentiate between survivors and non-survivors at day $28{ }^{16-20}$ IL-10 and IL-13 are also correlated to severity of infection, ${ }^{21}{ }^{22}$ whereas IL-8 is a predictive marker for multiple organ failure. ${ }^{23}{ }^{24}$ Interestingly, IL-6 seems to be more strongly associated with mortality compared to IL-1 $\beta$, IL-10 and TNF- $\alpha .{ }^{25}{ }^{26}$ On the basis of this knowledge, these cytokines will be investigated in the second study.

\section{Study III: vasoactive biomarkers in NSTI}

Nitric oxide (NO) is a biomarker with vasodilatory effects and is extensively released during septic shock. A previous study showed that nitrite/nitrate $\left(\mathrm{NO}_{2}^{-} /\right.$ $\mathrm{NO}_{3}^{-}$), which are the main metabolites of $\mathrm{NO}$, predicted development of septic shock more precisely compared to TNF- $\alpha$ and IL-6. ${ }^{27}$ Hydrogen sulfide $\left(\mathrm{H}_{2} \mathrm{~S}\right)$ is also a gasotransmitter and a signalling molecule with vasodilatory and vasoconstrictory effects. ${ }^{28}$ Additionally, $\mathrm{H}_{2} \mathrm{~S}$ may hold proinflammatory effects during septic shock, but the literature is scarce. ${ }^{29}{ }^{30}$ These biomarkers might play an important role in patients with NSTI and will be investigated in the third study.
Study IV: biomarkers and hyperbaric oxygen treatment

In Denmark, most patients with NSTI are treated with hyperbaric oxygen treatment (HBOT). Experimental studies with septic animals have demonstrated that HBOT decreases the concentration of proinflammatory cytokines and vasoactive biomarkers. ${ }^{31-33} \mathrm{~A}$ possible explanation may be that HBOT decreases organ ischaemia, which normally contributes to induction of cytokines and vasoactive biomarkers by a reduction in reactive oxygen species (ROS) and ICAM-1 expression. $^{3435}$ Another study in septic animals showed increased survival after HBOT due to an up-regulation of IL- $10^{36}$ and the results were dependent on the number of HBOT sessions and pressure applied. To the best of our knowledge, there are no published studies examining the effect of HBOT on biomarkers in patients with NSTI to date. This will be carried out in our fourth study.

\section{OBJECTIVES AND HYPOTHESIS}

The overall objective of the aforementioned studies is to investigate the immune response in patients with NSTI. The investigation will focus on biomarkers as prognostic markers of severity and mortality and whether HBOT is able to modulate these biomarkers. The overall hypothesis is that plasma biomarkers can be used as prognostic markers of severity and mortality in patients with NSTI and that HBOT reduces the inflammatory response and modulates host defence. Hopefully, the data will provide us with information that will allow us to:

- Identify patients with NSTI with increased risk of having an adverse outcome.

- Identify a subpopulation of patients with NSTI who are more likely to benefit from aggressive and extensive surgery, HBOT or immunoglobulin treatment.

- Identify patients with NSTI infected with streptococcus or anaerobic bacteria that might benefit from HBOT.

- Risk stratify and parse the heterogeneous group of patients with NSTI into a homogeneous group in whom the benefit from HBOT or immunoglobulin treatment is greater.

- Use the biomarkers as a surrogate outcome measure for therapeutic interventions.

\section{METHODS AND ANALYSIS}

\section{Study design}

The BIONEC study is a prospective, observational, pre hoc substudy as a part of the Scandinavian project called INFECT (ClinicalTrials.gov Identifier: NCT01790698) involving a total of five centres (Copenhagen University Hospital, Karolinska Institute, Blekinge Hospital, Sahlgrenska Hospital, University Hospital of Bergen) with the overall objective of improving the outcome in patients with NSTI. The BIONEC study is based on four studies; study I-III will investigate different groups of biomarkers and study IV will examine the effects of HBOT on these biomarkers. 


\section{Setting and study subjects}

The BIONEC study cohort consists of Danish patients in the Scandinavian INFECT project admitted at Copenhagen University Hospital, Rigshospitalet, with a diagnosis of NSTI. In order to validate our data collection and procedures, a group of 80-100 control subjects undergoing elective orthopaedic surgery at Rigshospitalet will also be included in this study. The patients will only be included once. They will be consecutively enrolled immediately on diagnosis using a predefined definition criteria for NSTI, as specified below. The first patient was enrolled on 26 February 2013. Owing to the low incidence of this disease, the enrolment period of this study will extend over 2.5 years (figure 1 ).

\section{Patients with NSTI}

Patients will be eligible if they are: (1) diagnosed with NSTI based on surgical findings (necrosis engaging any layers of the soft tissue compartments; dermis, subcutaneous fat, superficial fascia, deep fascia or muscle), (2) age $\geq 18$ years and (3) admitted to/planned to be admitted to the intensive care unit (ICU) and/or operated for NSTI at Rigshospitalet. Patients will be excluded if they are categorised as patients without NSTI in the operating theatre.

\section{Control patients}

Control patients will be eligible for inclusion if they are: (1) undergoing elective orthopaedic surgery (nonpathological fractures, joint replacement surgery, back surgery) at Rigshospitalet and (2) age $\geq 18$ years. Patients will be excluded if they: (1) have an ongoing infection or inflammatory condition.

\section{Data collection}

The blood samples will be drawn from an arterial line in patients with NSTI into collection tubes containing EDTA at four discrete time points: on admission and again during the following 3 days between 8:00 and 12:00 (table 1). Clinical data will be obtained during admission in the intensive care unit (table 2), but only for a maximum of 7 days. For the control group, the blood samples will be drawn by venous puncture at three discrete time points: baseline (preoperatively), 2-6 $\mathrm{h}$ postoperatively and the day after surgery between 8:00 and 12:00. The anticoagulated blood will be put on ice until centrifugation is performed (within $40 \mathrm{~min}$ of collection) at $3500 \mathrm{rpm}$ for $10 \mathrm{~min}$. The supernatant (serum) will subsequently be stored in $1 \mathrm{~mL}$ aliquots (Eppendorf vials) at $-80^{\circ} \mathrm{C}$ until analysation.

\section{Blood analysis}

Standard blood analyses such as sodium, potassium, haemoglobin, creatinine, leucocytes and CRP levels will be performed at the Department of Clinical Biochemistry, Rigshospitalet, as part of routine analyses.

\section{PTX3 measurement}

The concentration of PTX3 will be determined using anti-PTX3 monoclonal antibodies in an ELISA developed in the Laboratory of Molecular Medicine, Rigshospitalet, according to previously described procedures. ${ }^{10}$ In short, samples will be applied in triplicate and the interassay coefficient determined. PTX3 is stable during storage. Therefore, values from the control samples will be used to estimate normal values in noninfected patients undergoing surgery and compared with the values of patients with NSTI.
Figure 1 Study schematic diagram and patient inclusion. Inclusion will continue until 114 patients are included in study II and 112 patients in study IV (HBOT, hyperbaric oxygen treatment; IL-6, interleukin-6; $\mathrm{NO}_{2}^{-}$, nitrite; NSTI, necrotising soft tissue infections; PTX3, pentraxin-3).

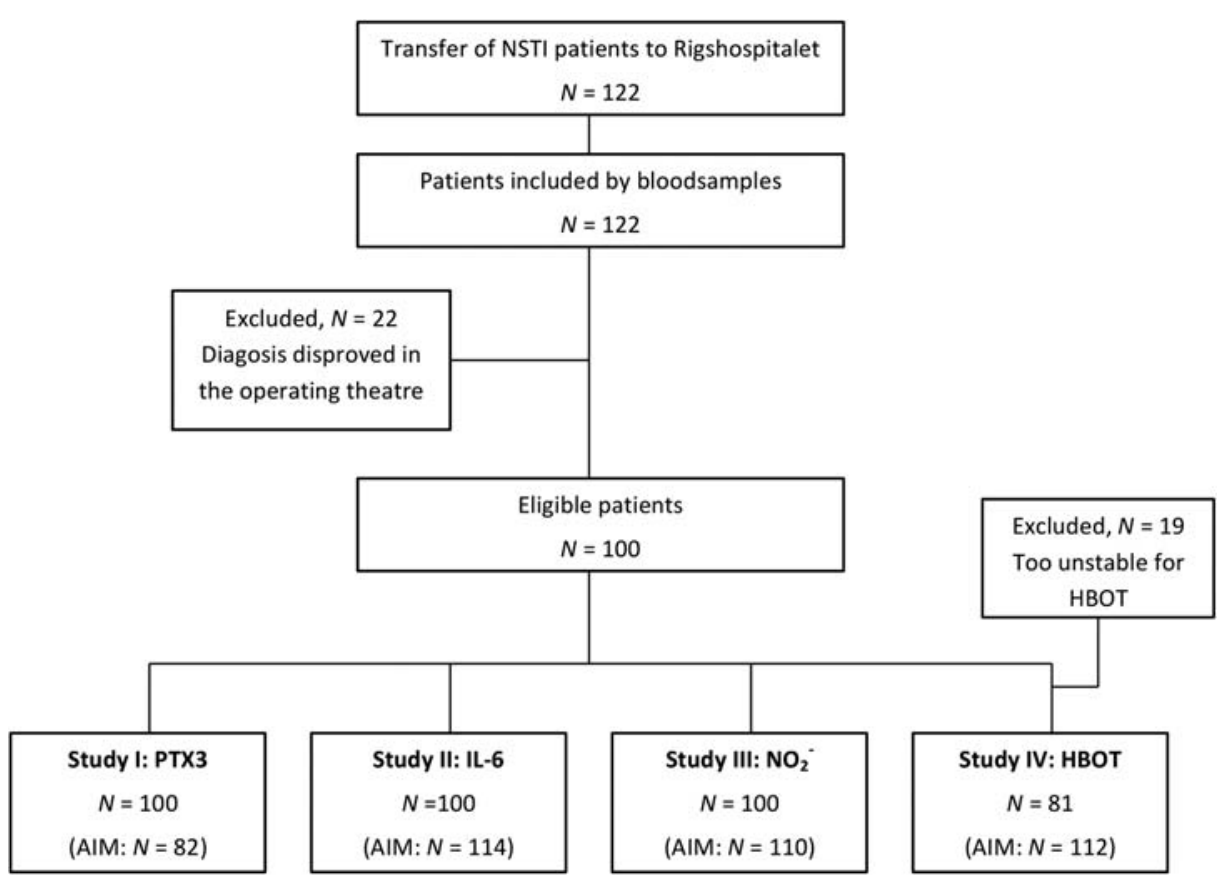

Transfer of NSTI patients to Rigshospitalet

Patients included by bloodsamples $N=122$ 
Table 1 Overview of the procedures involving blood sampling

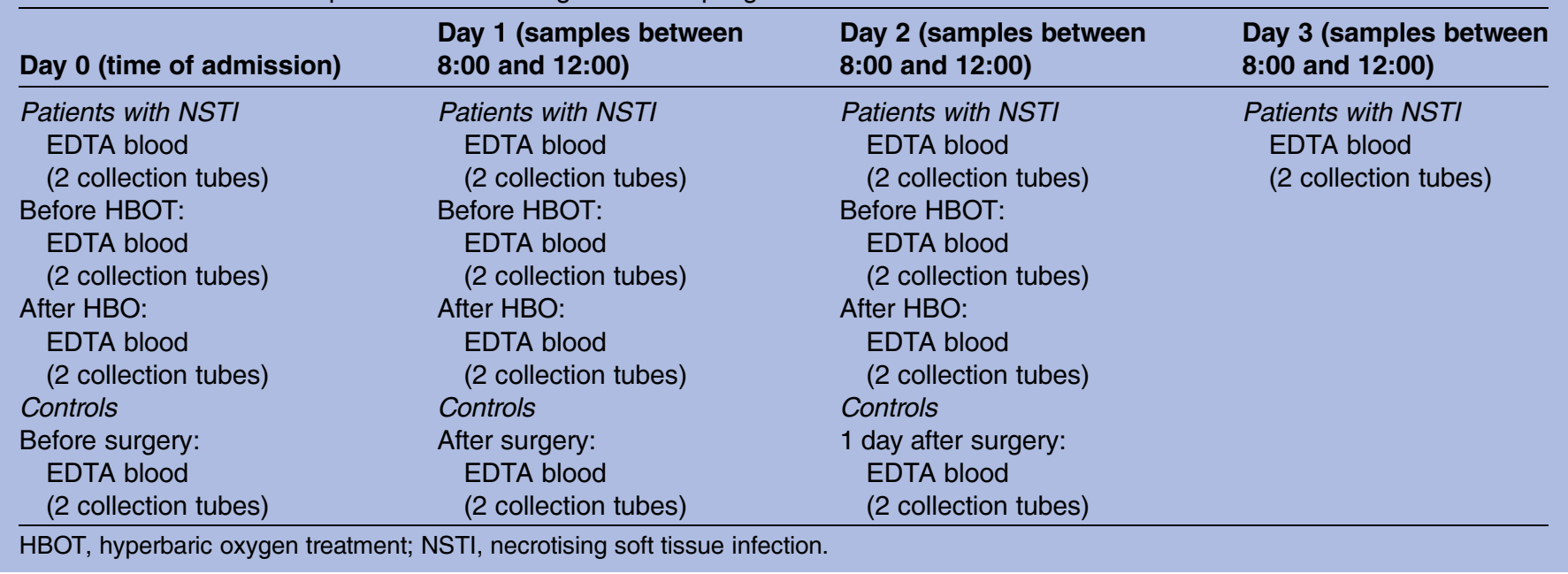

\section{Cytokine measurement}

Cytokines will be analysed with a multiplex sandwich immunoassay format with electrochemiluminescence. Briefly, plates precoated with capture antibodies for the specific cytokines, as described under outcome measures, will be incubated with plasma samples. Subsequently, detection antibodies will be added and the plates will be incubated once again. After washing, the detection levels will be determined.

Nitrate+nitrite measurement

NO levels in plasma have a short half-life; thus, the evaluation is based on its stable metabolites nitrate $\left(\mathrm{NO}_{3}^{-}\right)$and nitrite $\left(\mathrm{NO}_{2}^{-}\right)$. $\mathrm{NO}_{3}^{-}$measurements will be carried out in

Table 2 Baseline characteristics and clinical data

\begin{tabular}{|c|c|}
\hline Data & Description \\
\hline $\begin{array}{l}\text { Baseline } \\
\text { characteristics }\end{array}$ & $\begin{array}{l}\text { Sex and age } \\
\text { - Comorbidities } \\
\text { cancer, COLD, immunosuppression } \\
\text { - Body mass index } \\
\text { - Primary site of infection } \\
\text { - upper extremity, lower extremity, chest, abdomen, genital/perineum, head/neck, buttocks } \\
\text { - Cause of infection } \\
\text { - chronic wound/ulcer, injection, boil/furuncle, bite, idiopathic, trauma, postoperative incisional infection, } \\
\text { perirectal abscess, other } \\
\text { - Symptoms registered at primary hospital } \\
\text { - oedema, erythema, tachycardia, fever, bullae } \\
\text { - Microorganism } \\
\text { - } \text { Anaemolytic Streptococcus, Staphylococcus aureus, Clostridium spp., Gram-negative bacilli, } \\
\text { Time from admission at primary hospital to first operation/debridement } \\
\text { Time from admission to admission in the ICU } \\
\text { Steroid treatment (injection/oral intake) up to development of NSTI [Time Frame: Up to } 7 \text { days before } \\
\text { surgical diagnosis at primary hospital] }\end{array}$ \\
\hline $\begin{array}{l}\text { Clinical data } \\
\text { from the ICU }\end{array}$ & $\begin{array}{l}\text { MAP }(\mathrm{mm} \mathrm{Hg}) \\
\text { Heart rate }(\mathrm{bpm}) \\
\text { Arterial blood gas values: } \mathrm{pO}_{2}, \mathrm{pCO}_{2}, \mathrm{HCO}_{3}^{-} \text {, base excess, } \mathrm{pH} \\
\mathrm{K}^{+}, \mathrm{Na}^{+}, \mathrm{Ca}^{2+} \text {, glucose, creatinine, haemoglobin, haematocrit } \\
\text { Norepinephrine infusion } \\
\text { Ventilator treatment } \\
\text { Vasopressor treatment } \\
\text { Renal replacement treatment } \\
\text { - LRINEC score }\end{array}$ \\
\hline
\end{tabular}

COLD, chronic obstructive pulmonary disease; DM, diabetes mellitus; ICU, intensive care unit; IV, intravenous; LRINEC, Laboratory Risk Indicator for necrotising Fasciitis; MAP, mean arterial blood pressure. 
a two-step analysis; the evaluation is based on its chemiluminescence detection. Chemiluminescence detection is carried out in a reaction vessel containing $\mathrm{I}_{3}^{-}$reagent preequilibrated and purged with helium at room temperature $\left(21^{\circ} \mathrm{C}\right)$ using a Sievers (Boulder, Colorado, USA) Nitric Oxide analyser (NOA 280i) to detect NO in the gas phase at a sampling rate of $4 \mathrm{~s}^{-1} \cdot{ }^{37}$ As a control for higher NO levels, the Griess reaction method will be used with a standard commercial kit adapted for plasma samples. In short, samples are incubated with flavin adenine dinucleotide, reduced $\beta$-nicotinamide dinucleotide phosphate and nitrate reductase to reduce $\mathrm{NO}_{3}^{-}$to $\mathrm{NO}_{2}^{-}$at $37^{\circ} \mathrm{C}$ for $15 \mathrm{~min}$. The Griess reagent will then be added and the absorbance will be measured to evaluate total $\mathrm{NO}_{3}$-levels. Background absorbance will be measured for each sample and subtracted from total values. $\mathrm{NO}_{2}^{-}$measurements will be carried out in the same way. However, the enzymatic reduction step will be omitted. ${ }^{38}$

\section{Outcome measures}

Primary analysis

PTX3, $\mathrm{NO}_{2}^{-}$and IL-6 are thought to be early markers of disease severity in patients with NSTI. Therefore, the primary analysis will consist of determining the association between PTX3-, $\mathrm{NO}_{2}^{-}$and IL6-concentrations and septic shock (PTX3, $\mathrm{NO}_{2}^{-}$) or LRINEC $\geq 6$ (IL-6) in patients with NSTI at the time of admission to Rigshospitalet.

\section{Secondary analyses}

The secondary analyses will consist of evaluation of:

- Inflammatory biomarkers: The association between inflammatory biomarkers such as CRP, procalcitonin, MBL, ficolin 1-3, cytokines and septic shock, LRINEC $\geq 6$ and SAPS II at admission and during the following 3 days

- Vasoactive biomarkers: The association between vasoactive biomarkers such as $\mathrm{NO}_{3}^{-}$, L-arginine, asymmetric dimethylarginine, $\mathrm{H}_{2} \mathrm{~S}$, ROS, ICAM-1, E-selectin and septic shock, LRINEC $\geq 6$ and SAPS II at admission and during the following 3 days

- Comparison between inflammatory and vasoactive biomarkers of patients with NSTI and controls at admission and the second and third blood samples (days 1-2)

- Mortality at 28, 90 and 180 days

- To determine the prognostic value of the inflammatory and vasoactive biomarkers on survival, patients will be categorised to serum biomarker levels at admission. Patients will be divided into four groups according to quartiles of PTX3, IL- 6 and $\mathrm{NO}_{2}^{-}$and through dichotomisation based on the 95th centile of the control group

- A subgroup analysis of the biomarkers and severity of disease on admission and during the following 3 days: no sepsis, sepsis, severe sepsis and septic shock will be diagnosed according to standardised criteria ${ }^{39} 40$ and the biomarkers will be investigated to see if there is a correlation between disease severity and mortality in these groups

- A subgroup analysis to determine the effects of immunoglobulin on biomarkers (PTX3, $\mathrm{NO}_{2}^{-}$, IL-6) will be performed on patients randomised to immunoglobulin or saline on admission and during the following 3 days. The randomised double-blinded study was initiated in April 2014 and registered at ClinicalTrials.gov (NCT02111161).

Measurements and outcomes that will be obtained during the first 7 days in the ICU

- Amputation rate at any anatomical site

- ICU-scoring systems: SAPS II, APACHE II, SOFA, Anaya-score

- Multiple organ failure

- Number of surgical debridements

- Renal replacement therapy.

\section{Sample size}

Patients will be divided into two groups based on their haemodynamic stability, with or without septic shock, based on the definitions made at the ACCP/SCCM consensus conference. ${ }^{39} 40$ This comparison will be conducted due to a higher mortality rate in patients with septic shock, thereby making it a clinically relevant stratification. In our cohort, about $50-75 \%$ of the patients with NSTI are assumed to be in shock. The non-shock group consists of patients with and without sepsis and severe sepsis.

\section{Study I}

On the basis of previous studies that have used the same method of analysis, ${ }^{4} 710$ the investigators expect a mean PTX3-concentration on admission at $120 \mathrm{nmol} / \mathrm{L}$ in patients without septic shock and a mean PTX3-concentration at $210 \mathrm{nmol} / \mathrm{L}$ in patients with septic shock. With an estimated SD at $100 \mathrm{nmol} / \mathrm{L}$, the inclusion of 52 patients will be able to detect a significant difference with a statistical power of $90 \%$ at a $5 \%$ significance level. Since the groups are unequal, the investigators will need to include 82 patients $\left(\mathrm{N}^{\prime}=52(1\right.$ $\left.+4)^{2} / 4 \times 4\right)$.

\section{Study II}

In a pilot study with seven patients with NSTI, the investigators found a minimal clinically relevant difference in IL-6 concentration in patients with NSTI with LRINEC $<6$ and $\geq 6$ to be $1050 \mathrm{pg} / \mathrm{mL}$. Therefore, with an estimated SD at $2000 \mathrm{pg} / \mathrm{mL}$, the inclusion of 114 patients will be able to detect a significant difference with a statistical power of $80 \%$ at a $5 \%$ significance level.

\section{Study III}

On the basis of previous studies, ${ }^{38}{ }^{41-46}$ the investigators expect a mean $\mathrm{NO}_{2}^{-}$-concentration on admission of $90 \mu \mathrm{mol} / \mathrm{L}$ in patients without septic shock and a mean $\mathrm{NO}_{2}^{-}$-concentration at $145 \mu \mathrm{mol} / \mathrm{L}$ in patients with septic 
shock. With an estimated SD at $70 \mu \mathrm{mol} / \mathrm{L}$, the inclusion of 70 patients will be able to detect a significant difference with a statistical power of $90 \%$ at a $5 \%$ significance level. Since the groups are unequal, the investigators will need to include 110 patients $\left(\mathrm{N}^{\prime}=70(1+4)^{2} / 4 \times 4\right)$.

\section{Study IV}

The induction of IL-6 is fast (less than 1-2 h) with a relatively short half-life. These kinetics make it possible to investigate the direct effects of HBOT on the biomarker concentration. IL-6 also seems to be closely associated with mortality compared to other cytokines. ${ }^{25} 26$ To the best of our knowledge, there are no studies investigating the effect of HBOT on biomarkers. Therefore, we are estimating the sample size based on data from our pilot study. We hypothesise that HBOT reduces the inflammatory response; thereby reducing the plasma IL-6 levels after HBOT. However, some of the patients with NSTI are too haemodynamically unstable to receive HBOT. In these patients, we expect a higher inflammatory response than in the patients able to receive HBOT. Therefore, the investigators estimate a mean IL-6 concentration before HBOT of $3500 \mathrm{pg} / \mathrm{mL}$ (SD $1500 \mathrm{pg} / \mathrm{mL}$ ) and consider a reduction of $800 \mathrm{pg} / \mathrm{mL}$ to be clinically relevant. With $\alpha=0.05$ and a power of $80 \%, 112$ patients would be required to be treated with HBOT.

\section{Statistical analyses}

Non-parametric data will be log-transformed to obtain a normal distribution and will be presented as median values with IQR.

For the primary analysis, the groups will be compared using Mann-Whitney's U test at relevant time points. For categorical data, Fisher's exact test will be performed. For the subgroup analyses with the comparison of more than two groups (no sepsis, sepsis, severe sepsis, septic shock), a one-way ANOVA (parametric residuals) or a Kruskal-Wallis test (non-parametric residuals) will be used. Correlation analysis will be performed using Pearson correlation (parametric) or Spearman rank analysis (non-parametric). Receiver operating characteristic (ROC) curve analysis will be used to determine the diagnostic accuracy of PTX3, IL-6 and $\mathrm{NO}_{2}^{-}$as prognostic markers of severity and mortality in patients with NSTI. Optimal cut-off will be found by the Youden index maximum value. Survival analyses will be performed using Kaplan-Meier curves and the log-rank test. HRs with corresponding 95\% CIs will be determined using Cox regression models with adjustments for gender, age, comorbidities and SAPS II. A logistic regression model will be used to investigate the independent effects of PTX3, IL- 6 and $\mathrm{NO}_{2}^{-}$on the primary and secondary outcomes; results will be presented with ORs and $95 \%$ CIs. For analyses over time (within-group comparisons), a general linear model for repeated measures will be used to determine PTX3, IL- 6 and $\mathrm{NO}_{2}^{-}$in patients with NSTI with and without septic shock and between survivors and non-survivors from day 1 to day 3 and before and after HBOT (between-subject factor=treatment group and outcome. Within-subject factor=time). Results will be reported as statistically significant when $\mathrm{p}<0.05$. Corrections for multiple comparisons will be performed with Bonferroni or Dunn's test.

\section{ETHICS AND DISSEMINATION}

The study will be carried out in compliance with the national legislation and according to the Declaration of Helsinki. The National Ethics Committee and the Regional Scientific Ethics Committee of Copenhagen have approved the study (CVK-1211709 and H-2-2014-071). The Danish Data Protection Agency has approved the processing of personal data for the patients with NSTI and control patients (J. no. 30-0900 and J. no. 30-1282). If the patients with NSTI are deemed mentally incompetent, written informed consent is acquired from their next of kin as well as from their primary healthcare physician as requested by the legislation. This study poses little risk to the patients, as all the patients will receive standard treatment according to our state-of-the-art guidelines. Confidentiality is a part of the standard procedures: a unique research code will be assigned to each patient and there is a restricted access to the data.

Results will be disseminated at national and international conferences and then published in international peer-reviewed scientific journals. Positive, negative and any inconclusive results will be published. Additionally, national and international experts in the field will be involved in order to change management guidelines for patients with NSTI. The general public will be informed of the results through lay science articles in local and national newspapers with the specific aim of creating a better understanding of this infection and eliminating certain illusions about the 'flesh-eating bacteria'. Finally, the first author will send a lay summary of the final study results to the patients or their next of kin. The patients will thereafter have the opportunity to call the first author in case of questions.

Collaborators Professor, PhD Anna Norrby-Teglund, Centre for Infectious Medicine, Karolinska Institute, Huddinge F-59, S-141 86 Stockholm, Sweden. Study II will be performed at this centre under the supervision of Professor Anna Norrby-Teglund.

Contributors $\mathrm{MBH}$ and $\mathrm{OH}$ conceptualised the research design, wrote the research protocol, secured funding and are coordinating the project team. $\mathrm{MBH}$ was responsible for the sample size calculation and statistical methods and for the acquisition of data. US and PG contributed to the drafting of the protocol including a critical revision for important intellectual content. Additionally, ANT, US and PG contributed to the implementation of the study. $P G$ is responsible for the laboratory work in study I and US is responsible for the laboratory work in study III. All authors have read and approved the final version of the protocol.

Funding The INFECT project is supported by The European Seventh Framework Programme (grant number 305340). For more information about the European collaborative INFECT project, please visit http://www.fp7infect. eu/infect. This substudy is also supported by the Rigshospitalet Research Funds (grant number E-22514-02), the Aase and Ejnar Danielsens Foundation (grant number 10-001274), the Hans and Nora Buchards Foundation (grant 
number 7334), the Director Jacob Madsen and Olga Madsens Foundation (grant number 5323) and the Christian Larsen and judge Ellen Larsen's Foundation.

Competing interests None declared.

Patient consent Obtained.

Ethics approval The National Ethics Committee and the Regional Scientific Ethics Committee of Copenhagen have approved the study (CVK-1211709 and H-2-2014-071).

Provenance and peer review Not commissioned; externally peer reviewed.

Open Access This is an Open Access article distributed in accordance with the Creative Commons Attribution Non Commercial (CC BY-NC 4.0) license, which permits others to distribute, remix, adapt, build upon this work noncommercially, and license their derivative works on different terms, provided the original work is properly cited and the use is non-commercial. See: http:// creativecommons.org/licenses/by-nc/4.0/

\section{REFERENCES}

1. Hasham S, Matteucci P, Stanley PRW, et al. Necrotising fasciitis. BMJ 2005;330:830-3.

2. Sultan HY, Boyle AA, Sheppard N. Necrotising fasciitis. BMJ 2012;345:e4274.

3. Golger A, Ching S, Goldsmith $\mathrm{CH}$, et al. Mortality in patients with necrotizing fasciitis. Plast Reconstr Surg 2007:119:1803-7.

4. Muller B, Peri G, Doni A, et al. Circulating levels of the long pentraxin PTX3 correlate with severity of infection in critically ill patients. Crit Care Med 2001;29:1404-7.

5. al-Ramadi BK, Ellis M, Pasqualini F, et al. Selective induction of pentraxin 3 , a soluble innate immune pattern recognition receptor, in infectious episodes in patients with haematological malignancy. Clin Immunol Orlando Fla 2004;112:221-4.

6. Sprong T, Peri G, Neeleman C, et al. Pentraxin 3 and C-reactive protein in severe meningococcal disease. Shock Augusta $\mathrm{Ga}$ 2009;31:28-32.

7. Mauri T, Bellani G, Patroniti N, et al. Persisting high levels of plasma pentraxin 3 over the first days after severe sepsis and septic shock onset are associated with mortality. Intensive Care Med 2010;36:621-9.

8. Huttunen R, Hurme M, Aittoniemi J, et al. High plasma level of long pentraxin 3 (PTX3) is associated with fatal disease in bacteremic patients: a prospective cohort study. PLOS ONE 2011;6:e17653.

9. Uusitalo-Seppälä R, Huttunen R, Aittoniemi J, et al. Pentraxin 3 (PTX3) is associated with severe sepsis and fatal disease in emergency room patients with suspected infection: a prospective cohort study. PLOS ONE 2013;8:e53661.

10. Bastrup-Birk S, Skjoedt MO, Munthe-Fog L, et al. Pentraxin-3 serum levels are associated with disease severity and mortality in patients with systemic inflammatory response syndrome. PLOS ONE 2013;8: e73119.

11. Seller-Pérez G, Herrera-Gutiérrez ME, Lebrón-Gallardo M, et al. [Serum C-reactive protein as a marker of outcome and infection in critical care patients]. Med Clínica 2005;125:761-5.

12. Simon L, Gauvin F, Amre DK, et al. Serum procalcitonin and $C$-reactive protein levels as markers of bacterial infection a systematic review and meta-analysis. Clin Infect Dis Off Publ Infect Dis Soc Am 2004;39:206-17.

13. Uzzan $\mathrm{B}$, Cohen $\mathrm{R}$, Nicolas $\mathrm{P}$, et al. Procalcitonin as a diagnostic test for sepsis in critically ill adults and after surgery or trauma: a systematic review and meta-analysis. Crit Care Med 2006;34:1996-2003.

14. Reinhart K, Meisner M. Biomarkers in the critically ill patient: procalcitonin. Crit Care Clin 2011;27:253-63.

15. Kurt ANC, Aygun AD, Godekmerdan A, et al. Serum IL-1beta, IL-6, IL-8, and TNF-alpha levels in early diagnosis and management of neonatal sepsis. Mediators Inflamm 2007;2007:31397.

16. Panacek EA, Marshall JC, Albertson TE, et al. Efficacy and safety of the monoclonal anti-tumor necrosis factor antibody $F(a b ') 2$ fragment afelimomab in patients with severe sepsis and elevated interleukin-6 levels. Crit Care Med 2004;32:2173-82.

17. Heper Y, Akalin EH, Mistik R, et al. Evaluation of serum C-reactive protein, procalcitonin, tumor necrosis factor alpha, and interleukin-10 levels as diagnostic and prognostic parameters in patients with community-acquired sepsis, severe sepsis, and septic shock. Eur J
Clin Microbiol Infect Dis Off Publ Eur Soc Clin Microbiol 2006;25:481-91.

18. Wang $\mathrm{CH}$, Gee MJ, Yang $\mathrm{C}$, et al. A new model for outcome prediction in intra-abdominal sepsis by the linear discriminant function analysis of IL-6 and IL-10 at different heart rates. J Surg Res 2006;132:46-51.

19. Calandra T, Baumgartner JD, Grau GE, et al. Prognostic values of tumor necrosis factor/cachectin, interleukin-1, interferon-alpha, and interferon-gamma in the serum of patients with septic shock. Swiss-Dutch J5 Immunoglobulin Study Group. J Infect Dis 1990;161:982-7.

20. Riché $F$, Panis $Y$, Laisné $M J$, et al. High tumor necrosis factor serum level is associated with increased survival in patients with abdominal septic shock: a prospective study in 59 patients. Surgery 1996;120:801-7.

21. Collighan N, Giannoudis PV, Kourgeraki O, et al. Interleukin 13 and inflammatory markers in human sepsis. Br J Surg 2004;91:762-8.

22. Marchant A, Alegre ML, Hakim A, et al. Clinical and biological significance of interleukin-10 plasma levels in patients with septic shock. J Clin Immunol 1995;15:266-73.

23. El-Maghraby SM, Moneer MM, Ismail MM, et al. The diagnostic value of C-reactive protein, interleukin-8, and monocyte chemotactic protein in risk stratification of febrile neutropenic children with hematologic malignancies. J Pediatr Hematol Oncol 2007;29:131-6

24. Fujishima S, Sasaki J, Shinozawa $Y$, et al. Serum MIP-1 alpha and IL-8 in septic patients. Intensive Care Med 1996;22:1169-75.

25. Patel RT, Deen $\mathrm{KI}$, Youngs $\mathrm{D}$, et al. Interleukin 6 is a prognostic indicator of outcome in severe intra-abdominal sepsis. Br J Surg 1994;81:1306-8.

26. Harbarth S, Holeckova K, Froidevaux C, et al. Diagnostic value of procalcitonin, interleukin-6, and interleukin-8 in critically ill patients admitted with suspected sepsis. Am J Respir Crit Care Med 2001;164:396-402.

27. De Werra I, Jaccard C, Corradin SB, et al. Cytokines, nitrite/nitrate, soluble tumor necrosis factor receptors, and procalcitonin concentrations: comparisons in patients with septic shock, cardiogenic shock, and bacterial pneumonia. Crit Care Med 1997;25:607-13.

28. Skovgaard N, Gouliaev A, Aalling M, et al. The role of endogenous $\mathrm{H} 2 \mathrm{~S}$ in cardiovascular physiology. Curr Pharm Biotechnol 2011;12:1385-93.

29. Li L, Bhatia M, Moore PK. Hydrogen sulphide-a novel mediator of inflammation? Curr Opin Pharmacol 2006;6:125-9.

30. Li L, Bhatia M, Zhu YZ, et al. Hydrogen sulfide is a novel mediator of lipopolysaccharide-induced inflammation in the mouse. FASEB J Off Publ Fed Am Soc Exp Biol 2005;19:1196-8.

31. Lin HC, Wan FJ, Wu CC, et al. Hyperbaric oxygen protects against lipopolysaccharide-stimulated oxidative stress and mortality in rats. Eur J Pharmacol 2005:508:249-54.

32. Niu KC, Huang WT, Lin MT, et al. Hyperbaric oxygen causes both antiinflammation and antipyresis in rabbits. Eur J Pharmacol 2009;606:240-5.

33. Yu X, Li YG, He XW, et al. Hyperbaric oxygen reduces inflammatory response in acute pancreatitis by inhibiting NF-kappaB activation. Eur Surg Res Eur Chir Forsch Rech Chir Eur 2009;42:130-5.

34. Yamashita M, Yamashita M. Hyperbaric oxygen treatment attenuates cytokine induction after massive hemorrhage. $A m ~ J$ Physiol Endocrinol Metab 2000;278:E811-16.

35. Buras JA, Stahl GL, Svoboda KK, et al. Hyperbaric oxygen downregulates ICAM-1 expression induced by hypoxia and hypoglycemia: the role of NOS. Am J Physiol Cell Physiol 2000;278: C292-302.

36. Buras JA, Holt D, Orlow D, et al. Hyperbaric oxygen protects from sepsis mortality via an interleukin-10-dependent mechanism. Crit Care Med 2006;34:2624-9.

37. Yang BK, Vivas EX, Reiter CD, et al. Methodologies for the sensitive and specific measurement of S-nitrosothiols, iron-nitrosyls, and nitrite in biological samples. Free Radic Res 2003;37:1-10.

38. Aamand R, Dalsgaard T, Ho YCL, et al. A NO way to BOLD? Dietary nitrate alters the hemodynamic response to visual stimulation. Neurolmage 2013;83:397-407.

39. Bone RC, Balk RA, Cerra FB, et al. Definitions for sepsis and organ failure and guidelines for the use of innovative therapies in sepsis. The ACCP/SCCM Consensus Conference Committee. American College of Chest Physicians/Society of Critical Care Medicine. Chest 1992;101:1644-55

40. Levy MM, Fink MP, Marshall JC, et al. 2001 SCCM/ESICM/ACCP/ ATS/SIS International Sepsis Definitions Conference. Crit Care Med 2003;31:1250-6. 
41. Sjövall F, Morota S, Asander Frostner E, et al. Cytokine and nitric oxide levels in patients with sepsis-temporal evolvement and relation to platelet mitochondrial respiratory function. PLoS ONE 2014;9:e97673.

42. Mian Al, Aranke M, Bryan NS. Nitric oxide and its metabolites in the critical phase of illness: rapid biomarkers in the making. Open Biochem J 2013;7:24-32.

43. Hersch M, Scott JA, Izbicki G, et al. Differential inducible nitric oxide synthase activity in circulating neutrophils vs. mononuclears of septic shock patients. Intensive Care Med 2005;31:1132-5.
44. Dhillon SS, Mahadevan K, Bandi V, et al. Neutrophils, nitric oxide, and microvascular permeability in severe sepsis. Chest 2005;128:1706-12.

45. Mitaka C, Hirata Y, Yokoyama K, et al. Relationships of circulating nitrite/nitrate levels to severity and multiple organ dysfunction syndrome in systemic inflammatory response syndrome. Shock Augusta Ga 2003;19:305-9.

46. Strand OA, Leone A, Giercksky KE, et al. Nitric oxide indices in human septic shock. Crit Care Med 2000;28:2779-85. 